\title{
PERFIL E CRESCIMENTO DOS TEMAS "GOVERNANÇA CORPORATIVA" E "ESTRATÉGIA": UMA ANÁLISE DOS ÚLTIMOS 11 ANOS NOS PERIÓDICOS DA ÁREA DE ADMINISTRAÇÃO NO BRASIL PROFILE AND EVOLUTION OF CORPORATE GOVERNANCE AND STRATEGY ISSUES: AN ANALYSIS OF THE LAST ELEVEN YEARS IN THE AREA OF ADMINISTRATION JOURNALS IN BRAZIL
}

\section{Henrique César Melo Ribeiro}

Doutorando em Administração de Empresas pela Universidade Nove de Julho. Mestre em Administração de Empresas pela Universidade de Fortaleza (Unifor).

\section{Sérgio Nunes Muritiba}

Professor e pesquisador de Estratégia e Governança Corporativa, do Programa de Mestrado e Doutorado em Administração da Universidade Nove de Julho. Pesquisador visitante da Columbia Business School, EUA.

\section{Patricia Morilha Muritiba}

Doutora em Administração pela USP - Universidade de São Paulo. Mestre em Administração pela USP - Universidade de São Paulo. Professora do Programa de Mestrado e Doutorado em Administração da Universidade Nove de Julho

\section{RESUMO}

O objetivo deste estudo foi investigar o perfil das pesquisas e o crescimento dos temas "governança corporativa" e "estratégia" em conjunto nos artigos publicados nas Revistas Qualis B2 a A1, no período de 2000 a 2010. Analisaram-se 79 trabalhos publicados no referido período. Investigaram-se os seguintes aspectos: o crescimento dos temas e periódicos de destaque; as características de autoria; os autores com maior produção nestes temas; as referências mais citadas; as referências por período e as abordagens metodológicas. Foi um estudo bibliométrico, com abordagem quantitativa, utilizando também a estatística descritiva. Observou-se que os temas "governança corporativa" e "estratégia" estão em constante desenvolvimento teórico e metodológico; verificou-se que ambos os temas são interdisciplinares entre si; constatou-se que as publicações com os temas relacionados estão crescendo em número e em qualidade. Em suma, este estudo mostra que há grandes oportunidades para o crescimento e a consolidação dos temas "governança corporativa" e "estratégia" na literatura acadêmica nacional.

Palavras-chave: governança corporativa; estratégia; análise bibliométrica.

\section{ABSTRACT}

This study's objective was to investigate the research profile and evolution considering simultaneously the topics Corporate Governance and Strategy. It focused the studies published between 2000 and 2010 in journals evaluated as B2 to A1 according to Capes-Qualis. We analyzed 79 papers which were published under these criteria, investigating: the growth of determined topics and which journals published more on this subject; author characteristics; authors with more scientific contribution to these topics; highly cited references; analyses of the methodological choices. It consisted on a bibliometric study, with a quantitative approach, with the use of descriptive analysis. Results showed that: corporate governance and strategy are topics in constant growth and methodological development; these subjects are interdisciplinary; studies covering these topics are growing in number and quality. Finally, this study shows that there are big opportunities for the growth and consolidation of these two topics in the Brazilian literature.

Keywords: corporate governance; strategy; bibliometric analysis.

Henrique César Melo Ribeiro

hcmribeiro@hotmail.com
Sérgio Nunes Muritiba

smuritiba@gmail.com
Patricia Morilha Muritiba

pmorilha@gmail.com 


\section{INTRODUÇÃO}

A teoria da agência (Jensen \& MeCKLING, 1976) tem influenciado fortemente os estudos sobre governança corporativa (SAITO \& SILVEIRA, 2008; HUANG \& Ho, 2011), muito embora este tema seja abordado em múltiplas áreas do conhecimento e em várias perspectivas teóricas em estratégia (Rodrigues \& Malo, 2006). Porém, constatou-se não ser visível a integração direta da governança corporativa com as estratégias adotadas pelas organizações. De acordo com os autores Grün (2005), Koh, Laplante \& Tong (2007), Castro et al. (2009), García-Meca \& Sánchez-Ballesta (2009) e Delgado et al., (2010), contudo, as boas práticas de governança corporativa, por meio de seus mecanismos, têm relação direta ou indireta com os ganhos da gestão e são extremamente relevantes para a estratégia empresarial das corporações no longo prazo.

Desta forma, é importante existir uma investigação da difusão conjunta das temáticas "governança corporativa" e "estratégia" nas produções científicas, visando a desencadear futuros trabalhos correlatos e ou que envolvam esses temas. De acordo com o aporte teórico, constatou-se que existem outros estudos de cunho bibliométrico envolvendo o assunto "governança corporativa" e/ou "estratégia", porém espera-se, nesta pesquisa, avançar no assunto, apresentando um cenário das pesquisas nas revistas Qualis B2 a A1 (triênio 2007-2009), entre os anos de 2000 a 2010, a fim de demonstrar a importância e a emergência das temáticas em conjunto para os atuais e futuros pesquisadores.

Diante desse contexto e para suprir possíveis gaps de outros estudos bibliométricos realizados anteriormente sobre os temas, evidencia-se uma pergunta que fundamenta as linhas mestras deste estudo, ou seja, qual é o perfil das pesquisas e o padrão de crescimento das publicações nos temas "governança corporativa" e "estratégia" em conjunto nos artigos publicados nas revistas Qualis B2 a A1, no período de 2000 a 2010 ?

A pesquisa, portanto, tem como objetivo geral investigar o perfil das pesquisas e o crescimento dos temas "governança corporativa" e "estratégia" em conjunto nos artigos publicados nas revistas Qualis B2 a A1, no intervalo temporal compreendido entre 2000 e 2010.
Este artigo se divide em cinco partes. A primeira contempla a introdução. A segunda parte traz o referencial teórico, o qual busca evidenciar a governança corporativa como estratégia e o crescimento das temáticas "governança corporativa" e "estratégia" por meio de estudos bibliométricos na literatura acadêmica. Os procedimentos metodológicos empregados na pesquisa encontram-se explicitados na parte três. A quarta parte aborda a análise e a discussão dos resultados. Finalmente, na parte cinco, faz-se a conclusão do trabalho, indicando-se as limitações da pesquisa e as recomendações para estudos futuros.

\section{REFERENCIAL TEÓRICO}

Esta seção apresenta uma série de estudos acadêmicos nacionais e internacionais bibliométricos sobre os temas "governança corporativa" e "estratégia" ao longo dos últimos anos.

\subsection{Governança corporativa como estratégia}

A governança corporativa pode ser definida como um conjunto de boas práticas que têm papel preponderante no desempenho das empresas, maximizando seu fluxo de investimento e diminuindo o custo de capital (OMAn, 2001). Este assunto está ligado diretamente ao interesse de ter uma empresa bem administrada, organizada e preparada para revelar a todos os stakeholders interessados as nuances que envolvem sua gestão (NAscimento, BIANCHI \& TERRA, 2005).

Em suma, a governança corporativa eficiente maximiza a confiabilidade da empresa diante do mercado de capitais, gerando satisfação, confiança e segurança para os investidores, possibilitando que os capitais sejam encontrados mais facilmente e contribuindo para com a criação de valor nas firmas (Zomignani, 2003; Rocca, 2007).

O crescimento da participação de investimentos estrangeiros diretos e indiretos (BertucCl, Bernardes \& BRANDÃO, 2006), por meio dos investidores institucionais, em decorrência da abertura do capital de empresas, pode influenciar na maximização da riqueza das corporações, surgindo assim problemas inerentes à organização no que tange ao controle e à forma de gestão. Remete-se, assim, a forma da estrutura de controle, podendo aparecer conflitos de interesses 
entre os acionistas e os executivos principais (DEDONATTO \& BEUREN, 2010) ou entre os acionistas majoritários e minoritários (Rogers, Mendes-DA-SILVA \& PaULA, 2008).

Alguns estudos evidenciaram que a estrutura de controle de empresas nacionais caracteriza-se por apresentar alto grau de concentração de votos sob o controle do acionista majoritário e por haver ampla utilização da emissão de ações preferenciais, estas sem direito a voto (Saito \& Silveira, 2008; Silveira, Perobelli \& Barros, 2008; RosSOnI \& Machado-DA-SILVA, 2010).

Diante do exposto, observou-se que o conjunto das boas práticas da governança corporativa, quando adotado na gestão da organização, objetiva proteger e assegurar os interesses dos investidores e minimizar os conflitos entre os agentes de dentro e fora da organização, ou seja, a adoção das boas práticas de governança corporativa é importante para as empresas, pois contribui para o processo de evitar a destruição de valor corporativo devido a problemas de controle de propriedade entre grupos de acionistas.

Salienta-se que os princípios balizadores da governança corporativa - transparência (disclosure), prestação de contas (accountability), equidade (fairness) e cumprimento de normas (compliance) - são essenciais para mitigar conflitos entre os grupos de acionistas controladores e minoritários, e ainda assegurar não só aos investidores, mas também aos proprietários, gestores e demais stakeholders uma gestão eficiente e eficaz (Bogoni et al., 2010), proporcionando assim um maior desempenho organizacional no tocante à criação de valor e perpetuidade da empresa.

Fazer gestão desta natureza requer a criação de uma cultura com disclosure, apoiada num crescente respeito aos direitos dos investidores e demais stakeholders da organização, que, apesar de não serem acionistas, são afetados pelas ações e estratégias empresariais (Mendes-da-Silva et al., 2009; DedonatTo \& BEUREN, 2010). Nesta perspectiva, mostraram-se relevantes práticas de governança corporativa (MENDES-DA-Silva, 2003; Grün, 2005; Koh, LapLANTE \& Tong, 2007; Castro et al., 2009; García-Meca \& SánchezBallesta, 2009; Delgado et al., 2010) nas estratégias das empresas.

Constatou-se, assim, terem relevância as boas práticas de governança corporativa nas estratégias adotadas pelas organizações, pois, de acordo com vários estudos (Bronzo \& HONÓRIO, 2005; GRÜN, 2005; Rogers, Mendes-da-Silva \& Paula, 2008; Santos, Antunes Júnior \& Leis, 2008; Marques \& Costa, 2009), as boas práticas, por meio de seus mecanismos, têm relação direta com a gestão e são extremamente importantes para as decisões estratégicas, figurando como alternativa para atingir desempenho superior por parte das empresas (Mendes-DA-Silva, 2003), isto é, a governança corporativa e a estratégia são determinantes para o desempenho empresarial (VAN DER WALT, INGLEY \& DIACK, 2002; MENDES-DA-SILVA, 2003).

\subsection{Governança corporativa e estratégia: estudos bibliométricos}

Define-se aqui, como estratégia empresarial, o padrão de decisões em uma empresa que determina e revela seus objetivos, propósitos ou metas (MINTZBERG \& Quinn, 2001), devendo estar associada à criação de valor para os acionistas, clientes e demais stakeholders (PORTER, 1999).

As primeiras publicações sobre governança corporativa e estratégia em periódicos da área de administração ocorreram na década de 1970 e contribuíram para disseminar os temas. São elas: Jensen \& Meckling (1976), Bowman (1979); Freeman \& Reed (1983); Williamson (1985); Boyd (1995); Stroh et al. (1996); Roth \& O'Donnell (1996); Doherty (1999); Denis, Denis \& Sarin (1999) e Collin \& Bengtsson (2000).

Porém, os trabalhos bibliométricos de publicações sobre governança corporativa e ou estratégia têm sido desenvolvidos e vistos tanto no âmbito nacional como internacional recentemente. Tal constatação deu-se em virtude das buscas destas publicações para melhor fomento da referida pesquisa, no que se refere à comparação das informações destas com as informações geradas por outras pesquisas correlatas. Diante disso, ressaltam-se, a seguir, alguns trabalhos e seus aspectos relevantes, que de maneira preponderante auxiliaram esta pesquisa quanto à compreensão do que já foi realizado sobre as temáticas "governança corporativa" e "estratégia".

Souza \& Borba (2007) analisaram artigos publicados no exterior que discutiam políticas de remuneração em governança corporativa. Verificouse que, no ano de 2005, foi encontrada a maior quantidade de artigos publicados sobre o assunto; e, 
quanto aos países focados nas pesquisas, o destaque foi dado ao continente americano, o qual totalizou $66 \%$ da amostra de artigos empíricos.

Bernardi (2008) buscou conhecer as características da produção sobre governança corporativa na perspectiva das publicações acadêmicas pela visão da ética empresarial. Os resultados obtidos parecem indicar uma recorrência maior de estudos desenvolvidos sob a temática da governança corporativa nas áreas vinculadas à administração geral e finanças.

Martins, Hildebrand \& Ziviani (2008) levantaram o estado da arte da produção científica, bem como analisaram as contribuições teóricas e empíricas sobre governança corporativa a partir dos congressos da Anpad, no período de 2000 a 2007. Destacou-se uma preponderância dos estudos na área de finanças em relação a organizações e estratégia.

Bianchi, Silva \& Gelatti (2009) identificaram o perfil das pesquisas e a evolução do tema "governança corporativa" nos artigos apresentados nos Encontro da Associação Nacional de Pós-Graduação e Pesquisa em Administração - EnAnpad, no período de 1999 a 2008. Observou-se, na fundamentação teórica apresentada nos artigos, a concentração das pesquisas sobre o tema na área de finanças; a partir de 2003, começaram a ser publicados trabalhos relacionados a outras áreas.

García-Meca \& Sánches-Ballesta (2009) fizeram uma meta-análise com 35 estudos com o intuito de examinar os efeitos da governança corporativa e os ganhos de resultado na gestão, por meio do gerenciamento dos conselhos de administração e estrutura de propriedade. Constatou-se ocorrer de maneira moderada uma relação entre a governança corporativa, por meio de seus mecanismos, e os ganhos de resultado na gestão.

Muritiba et al. (2010) mapearam a produção científica sobre governança corporativa em periódicos brasileiros, Qualis B2 a A1, nas áreas de administração, economia e contabilidade de 1998 a 2009. Os resultados mostraram que a área de governança corporativa vem evoluindo em número de artigos publicados e que se caracteriza por estar baseada em teoria recente.

Huang \& Ho (2011) fizeram uma análise bibliométrica sobre governança corporativa através do Social Science Citation Index nas áreas de finanças, economia, administração e negócios de 1992 a 2008. Os resultados evidenciam que a produção anual dos artigos sobre a temática governança corporativa aumentou regularmente.

Bertero, Vasconcelos \& Binder (2003) apresentaram um levantamento sistemático e uma avaliação crítica da produção científica em estratégia empresarial no Brasil. Concluiu-se que a produção científica não se distancia dos pontos principais do histórico da área no Brasil e que ainda está concentrada em um número relativamente reduzido de autores.

Saraiva \& Carrieri (2009) investigaram os índices de similaridade de conteúdo dos artigos publicados no Encontro de Estudos em Estratégia (3Es) como uma forma de avaliar a qualidade e a originalidade da produção acadêmica no Brasil, especificamente nessa disciplina. Apresentou-se uma reflexão crítica sobre os propósitos e critérios de avaliação utilizados para a definição da publicação acadêmica nesses encontros.

Serra \& Ferreira (2010) fizeram um estudo bibliométrico, cujo objetivo foi compreender a evolução dos conceitos e das obras sobre estratégia. Verificouse que as evoluções na atividade econômica influenciam o foco teórico da estratégia em múltiplas dimensões.

Walter et al. (2010) analisaram a cooperação entre pesquisadores de diferentes instituições, a internacionalização dessas cooperações e a rotatividade de autores na produção científica na área de estratégia no Brasil. Concluiu-se que a produção científica brasileira, na área de estratégia, necessita de investimentos em sua internacionalização, na densidade de suas cooperações e na permanência dos pesquisadores.

Percebeu-se que a quantidade de pesquisas bibliográficas em governança corporativa e/ou estratégia tende a se expandir, surgindo gradativamente diversas subáreas, ou seja, no bojo deste processo, observou-se o crescimento gradativo de estudos sobre a produção científica nos referidos temas.

\section{PROCEDIMENTOS METODOLÓGICOS}

Este estudo tem por objetivo mapear a produção científica sobre os temas "governança corporativa" e "estratégia" em periódicos brasileiros, ou seja, investigar 
o perfil das pesquisas e o crescimento dos temas "governança corporativa" e "estratégia" nos artigos publicados nas revistas brasileiras classificadas pelo sistema Capes ${ }^{1}$, como Qualis B2 a A1, no período de 2000 a 2010.

Assim, trata-se de um estudo de análise bibliométrica, que se destina a quantificar, analisar e avaliar a produção científica do tema, norteando rumos e estratégias para futuras pesquisas (COOPER \& LINDSAY, 1998; Leite FilHo, 2008). Há quatro etapas importantes adicionais à etapa de formulação do problema de pesquisa bibliométrica: a escolha da literatura analisada, a avaliação dos dados coletados, a análise e interpretação das informações e a apresentação dos resultados (COOPER \& LINDSAY, 1998). A escolha de qual literatura será analisada é um dos pontos-chave de análises do gênero, pois define o escopo do estudo e pode impactar sua validade (SIngleton \& Straits, 1999).

A bibliometria desenvolveu-se mediante a elaboração de leis empíricas sobre o comportamento da literatura (Araújo, 2006). Nesse cenário, é importante conhecer as três leis básicas da bibliometria para o melhor entendimento dos dados. Elas são oriundas, respectivamente, de três pesquisadores que se destacam por suas importantes descobertas: Bradford, Zipf \& Lotka (VANTI, 2002), sendo assim as mais comumente utilizadas e relacionadas à produtividade científica (Bufrem \& Prates, 2005).

A Lei de Bradford ou Lei da Dispersão mensura o nível de atração dos periódicos sobre determinado tema (Quoniam et al., 2001; MoretTI \& Campanario, 2009; PINTO, IgAMI \& BRESSSIANI, 2010).

Já a Lei de Lotka ou Lei do Quadro Inverso evidencia a produtividade e as citações de autores por meio de um modelo de distribuição de tamanho-frequência em um conjunto de artigos, concentrando-se em aspectos de coautoria (VANTI, 2002; CARDOSO et al., 2005; MoReTtI \& CAMPANARIO, 2009; GAZDA \& QuANDT, 2010).

E, no que se refere à Lei de Zipf ou Lei do Mínimo Esforço, calcula-se a quantidade de ocorrências das palavras em vários textos, criando uma lista de termos de uma determinada temática sendo utilizada para observar qual tema científico é tratado nos artigos (QuONIAM et al., 2001; VANTI, 2002; CARDOSO et al., 2005; MoretTI \& CAMPANARIO, 2009).

\footnotetext{
${ }^{1}$ Coordenação de Aperfeiçoamento de Pessoal de Nível Superior.
}

Salienta-se que a este grupo de leis agregaramse, a posteriori, outros estudos que configuram o corpo das preocupações dos pesquisadores da informação, a saber: Lei de Goffmam; a frente de pesquisa ou elitismo; e a obsolescência/vida média/idade da literatura (AlvARADO, 1984).

Neste estudo, pretendeu-se analisar a produção nacional sobre os temas. Para isso, foi escolhida uma amostra de periódicos nacionais relevantes. A relevância foi dada pela classificação dos periódicos na lista Qualis, da Coordenação de Aperfeiçoamento de Pessoal no Nível Superior (Capes). Como forma de analisar a produção científica dos programas de mestrado e doutorado no País, o órgão classifica periódicos e congressos nacionais e internacionais de acordo com sua relevância para a Administração. É divulgada, então, a listagem conhecida como Qualis, "uma lista de veículos utilizados para a divulgação da produção intelectual dos programas de pós-graduação stricto sensu (mestrado e doutorado), classificados quanto ao âmbito de circulação (local, nacional, internacional) e à qualidade $(A, B, C)$, por área de avaliação" (CAPES, 2011).

Foram escolhidos os periódicos classificados com a nota A1, A2, B1 e B2 pela Qualis da área de Administração (triênio 2007-2009). Este representa o extrato superior de avaliação. Dentre os periódicos evidenciados, a amostra descreve aqueles que, pela temática, podem conter estudos de governança corporativa e estratégia. Desta forma, chegou-se à relação contemplada no Quadro 1.

O Quadro 1 mostra, portanto, que neste estudo foram analisadas 13 revistas científicas nacionais. A coleta de dados foi feita buscando-se, nessas revistas, artigos publicados entre 2000 e 2010. Cada um dos periódicos relacionados no quadro anterior passou por um processo de busca de artigos, que correspondeu à temática deste estudo. Em muitas das revistas, os artigos estão disponíveis eletronicamente; em compensação, em outras, a busca foi feita de forma manual, consultando-se os exemplares disponíveis em biblioteca.

O critério utilizado para a seleção dos artigos foi baseado na ocorrência das terminologias empregadas para identificar as abordagens da governança eorporativa e estratégia, conforme localizadas não simultaneamente no título, no resumo, nas palavras- 
Quadro 1: Classificação das revistas

\begin{tabular}{|c|c|c|c|c|}
\hline Título do periódico & Sigla* & ISSN & Categoria & Nota \\
\hline Brazilian Administration Review & BAR & $1807-7692$ & Nacional & A2 \\
\hline Revista de Administração Pública & RAP & 0034-7612 & Nacional & A2 \\
\hline Cadernos Ebape ${ }^{2}$ & Ebape & 1679-3951 & Nacional & B1 \\
\hline RAC-Eletrônica & RAC-e & $1981-5700$ & Nacional & B1 \\
\hline Revista de Administração de Empresas & RAE & $0034-7590$ & Nacional & B1 \\
\hline RAE-Eletrônica & RAE-e & $1676-5648$ & Nacional & B1 \\
\hline Revista de Administração Contemporânea & RAC & $1415-6555$ & Nacional & B1 \\
\hline Revista de Administração Mackenzie & RAM & $1518-6776$ & Nacional & B1 \\
\hline Brazilian Business Review & BBR & $1807-734 x$ & Nacional & B2 \\
\hline Rausp-Eletrônica & Rausp-e & 1983-7488 & Nacional & B2 \\
\hline Revista Eletrônica de Administração & REAd & $1413-2311$ & Nacional & B2 \\
\hline Revista Base & Base & $1807-054 x$ & Nacional & B2 \\
\hline Revista de Administração da USP3 & Rausp & $0080-2107$ & Nacional & B2 \\
\hline
\end{tabular}

Fonte: Capes (2011)

Nota: a maioria das revistas tem a sua sigla; para algumas, no entanto, foram criadas siglas para serem utilizadas em gráficos e quadros.

chave, na fundamentação teórica e/ou nas referências bibliográficas dos artigos deste estudo.

Para selecionar os artigos relevantes, foram utilizadas as palavras-chave relacionadas no Quadro 2. É importante notar que não foram usadas as palavraschave de estratégia ou correlatas simultaneamente, de forma que foram selecionados todos os artigos que tinham ao menos uma das palavras de estratégia relacionadas abaixo. Porém, a palavra-chave "governança corporativa" deveria aparecer no artigo, simultaneamente, com pelo menos uma das palavraschave de "estratégia". Assim, foram selecionados todos os artigos que tinham ao menos uma palavra- chave: "governança corporativa" e outra de "estratégia".

Após a escolha dos artigos, estes foram catalogados utilizando-se o software Mendeley Desktop, que organiza referências bibliográficas. Eles também foram analisados conforme os seguintes indicadores: diversidade dos temas abordados; periódicos de destaque; características de autoria; autores com maior produção nestes temas; autores mais citadas; abordagens metodológicas; e referências por período. A análise dos indicadores acima foi feita de forma quantitativa, utilizando-se estatística descritiva para tais indicadores. Os resultados estão apresentados no item a seguir.

Quadro 2: Palavras-chave

\section{Palavras-chave}

Governança corporativa; adaptação estratégica; aliança(s) estratégica(s); análise de competitividade; arenas competitivas; balanced scorecard; BSC; cadeia(s) de valor; capacidade(s) dinâmica(s); cenário(s) estratégico(s); desempenho competitivo; estratégia corporativa; estratégia de administração pública; estratégia de aprendizagem; estratégia de competição; estratégia de cooperação; estratégia de coopetição; estratégia de marketing; estratégia de tecnologia; estratégia de Tl; estratégia empresarial; estratégia global; estratégia; estratégias corporativas; estratégias de manufatura; estratégias de PME; estratégias empresariais; estratégias; fundamentos econômicos; fundamentos organizacionais; fusões, aquisições e incorporações; hipercompetição; inovação; internacionalização; planejamento estratégico; processo decisório estratégico; recurso(s) e competência(s); redes de valor; redes estratégicas; responsabilidade social; teoria dos stakeholders; tipologias estratégicas; vantagem competitiva; VBR; visão baseada em recursos.

Fonte: elaborado pelos autores.

\footnotetext{
2 Escola Brasileira de Administração Pública e Empresas.

${ }^{3}$ Universidade de São Paulo.
} 


\section{ANÁLISE E DISCUSSÃO DOS RESULTADOS}

A finalidade deste capítulo foi mobilizar a análise bibliométrica dos 79 artigos publicados nas Revistas Qualis B5 a A1. Para tanto, foi subdivida a análise dos resultados em seis tópicos, como segue: (I) crescimento dos temas e periódicos de destaque; (II) características de autoria; (III) autores com maior produção nestes temas; (IV) referências mais citadas; (V) referências por período; (VI) abordagens metodológicas.

\subsection{Crescimento dos temas e periódicos de destaque}

O Gráfico 1 evidencia o número de artigos publicados sobre os temas "governança corporativa" e "estratégia" no período analisado.

Ao se analisar o Gráfico 1, ressalta-se que há pouca ocorrência de estudos relacionados às temáticas nos anos de 2000 a 2002. Porém, a partir do ano de 2003 , houve um aumento substancial sobre os temas, apresentando uma evolução percentual aproximada de $200 \%$ deste ano para 2010. Corroboraram em parte a afirmação os autores Bernardi (2008), Martins, Hildebrand \& Ziviani (2008), Bianchi, Silva \& Gelatti (2009); Muritiba et al. (2010); Huang \& Ho (2011), no âmbito da governança corporativa; e os autores Walter et al. (2010) no que se refere ao tema "estratégia".
Uma provável explicação para tal fenômeno podem ter sido as publicações internacionais de Jensen \& Meckling (1976), Bowman (1979); Freeman \& Reed (1983); Williamson (1985); Boyd (1995); Stroh et al. (1996); Roth \& O'Donnell (1996); Doherty (1999); Denis, Denis \& Sarin (1999) e Collin \& Bengtsson (2000), legitimadas, que tiveram uma forte influência na integração das temáticas "governança corporativa" e "estratégia", as quais precederam estes períodos e que, de alguma forma, impactaram diretamente e/ou indiretamente o fomento (impulsão) de novas pesquisas sobre os assuntos, já que foram as mais citadas nos estudos

O Gráfico 2 mostra as revistas de administração da Capes com maior número de artigos sobre os temas integrados de "governança corporativa" e "estratégia". A análise do Gráfico 2 das principais revistas Qualis deste estudo evidencia uma hierarquia de onde está publicada a maior parte dos artigos sobre governança corporativa e estratégia. Observa-se que mais da metade, ou seja, 56,96\% dos artigos publicados estão contemplados nas revistas RAC, BAR e RAE.

Tal informação foi confirmada, em parte, pelos autores Bertero, Vasconcelos \& Binder (2003), na temática de "estratégia", e por Muritiba et al. (2010), no tema "governança corporativa". Constatou-se também que, dentre as 13 revistas pesquisadas, $30,77 \%$ não tiveram nenhuma publicação sobre as

Gráfico 1: Crescimento dos artigos por ano

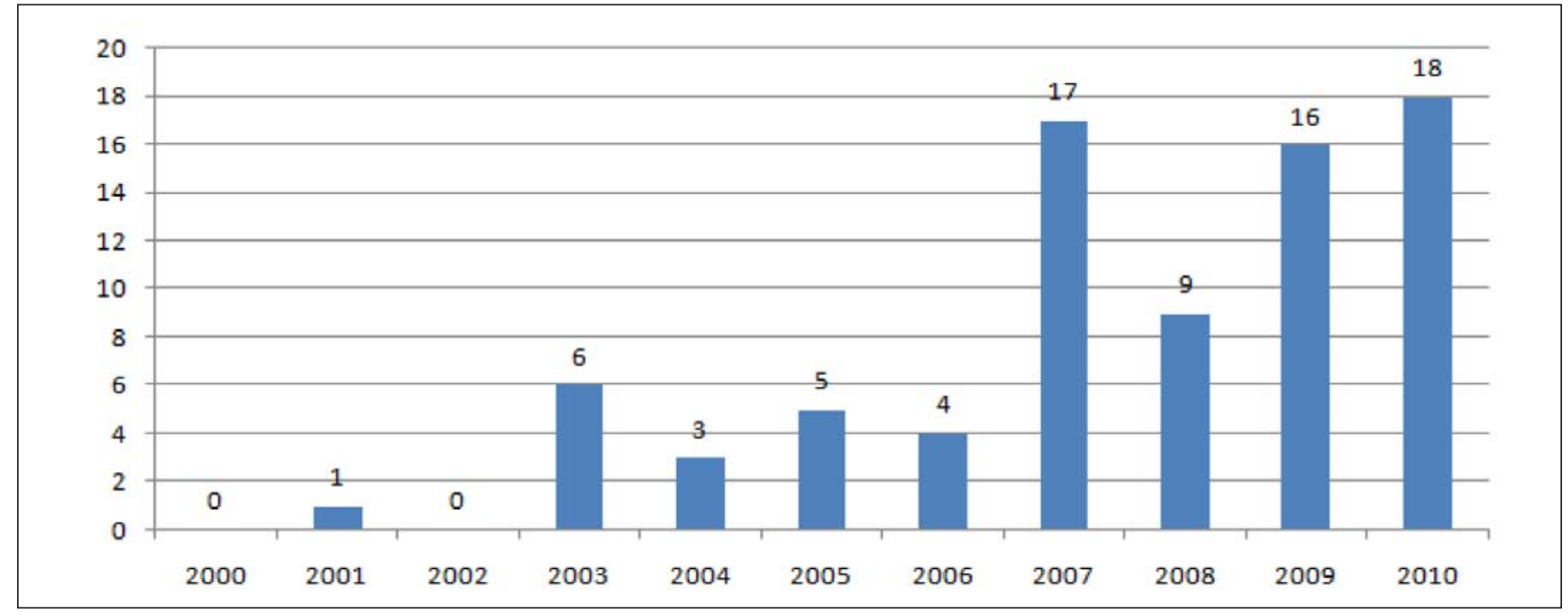

Fonte: elaborado pelos autores. 
Gráfico 2: Número de artigos por revista

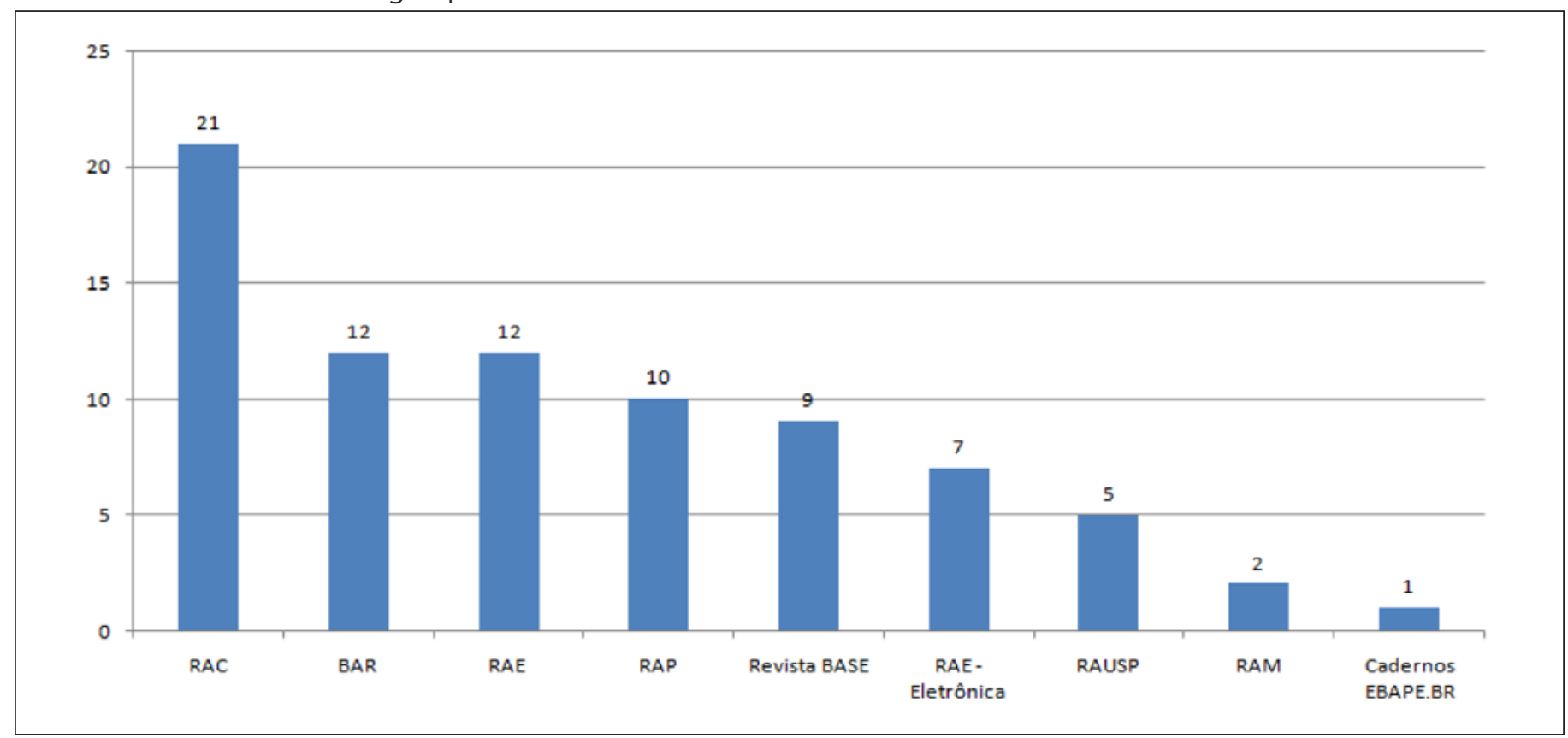

Fonte: elaborado pelos autores.

temáticas integradas durante o período pesquisado. Dentre elas, citam-se: RAC-e, BBR e REAd.

Diante do exposto, a Lei de Bradford corrobora os achados, pois ela se reporta à dispersão dos periódicos científicos, evidenciando seus respectivos graus de relevância na literatura acadêmica, ou seja, Bradford compreendeu que um núcleo essencial de periódicos forma a base da literatura para todas as disciplinas, e que, portanto, a maioria dos trabalhos importantes é publicada em poucas revistas (TESTA, 1998), sendo consideradas assim revistas de maior fator de impacto.

\subsection{Características de autoria}

O número de autores que publicam cada artigo evidencia redes e parcerias entre eles. O Gráfico 3 apresenta a frequência de artigos de autoria individual e com mais autores por artigo.

Ao se analisar o Gráfico 3, verifica-se que os artigos individuais ocorrem em menor número em comparação com a ocorrência de artigos de dois ou mais participantes, podendo ser um indicativo da existência de grupos de pesquisa sobre as temáticas.

Gráfico 3: Autoria dos artigos por ano

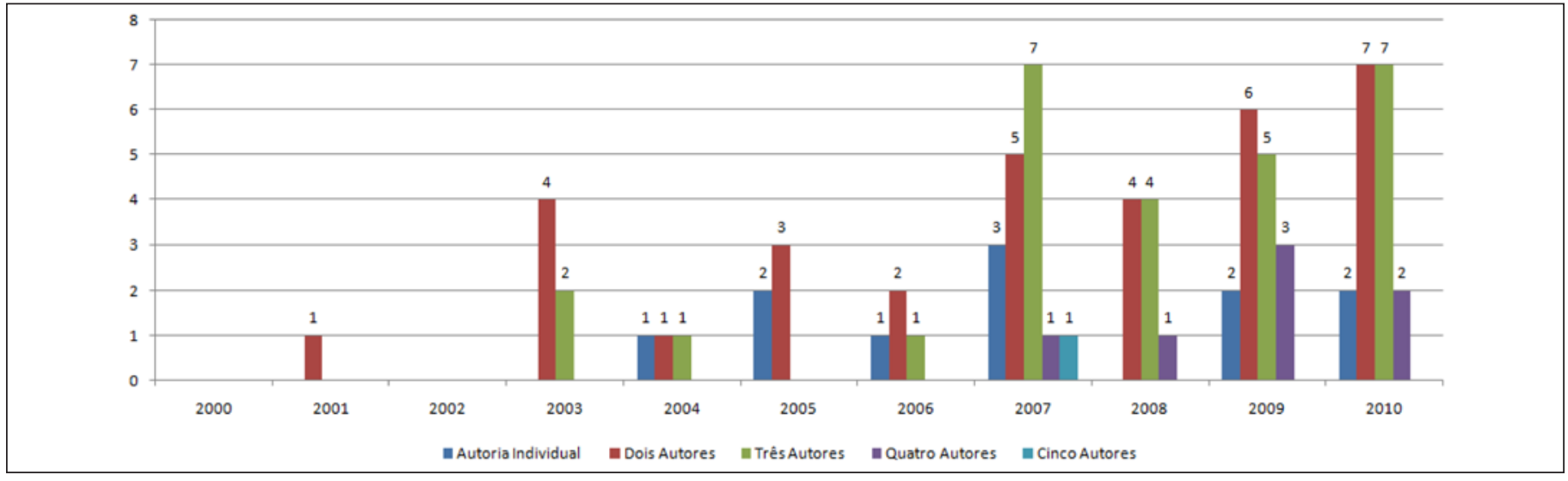


Como pode ser observado, prevalece o número de artigos publicados com dois autores, representando aproximadamente $42 \%$ da amostra. Tal fato é visto similarmente nos estudos dos autores Bertero, Vasconcelos \& Binder (2003), Martins, Hildebrand \& Ziviani (2008); Bianchi, Silva \& Gelatti (2009); Muritiba et al. (2010); e Huang \& Ho (2011).

O Gráfico 3 ainda evidencia que as publicações com dois e três autores começaram a tomar espaço a partir do ano de 2001 e 2003, respectivamente, e que os artigos de quatro e cinco participantes iniciaram-se a partir de 2007. Em relação aos trabalhos sem parceria, constatou-se certa constância nos anos de 2004 a 2010, havendo uma ausência no ano de 2008 e um aumento incremental no ano de 2007. Tais dados sugerem uma consolidação de grupos de pesquisa sobre governança corporativa e estratégia, contribuindo assim para o fomento dos referidos temas em conjunto no âmbito acadêmico e para a maior viabilidade na realização de novos projetos de inicia- ção científica, pois alunos poderão ingressar e aperfeiçoar a disseminação das temáticas em questão.

\subsection{Autores com maior produção nestes temas}

A análise dos autores que mais publicam em determinado assunto revela, primeiramente, a maturidade da área. Áreas mais maduras tendem a ter pesquisadores com histórico de pesquisa relevante (NEDERHOF, 2006).

O Gráfico 4 contempla os nomes de Richard Saito e Wesley Mendes-da-Silva como os autores que mais publicam artigos sobre as temáticas conjuntas de "governança corporativa" e "estratégia" no período analisado, ou seja, quatro publicações. Em seguida, evidencia-se o autor Joaquim Rubens Fontes Filho, com três artigos. Tais informações foram corroboradas em parte pelos autores Walter et al. (2010), no tema "estratégia", e por Martins, Hildebrand \& Ziviani (2008); Bianchi, Silva \& Gelatti (2009); e Muritiba et al. (2010), na temática "governança corporativa".

Gráfico 4: Publicação dos autores no período pesquisado

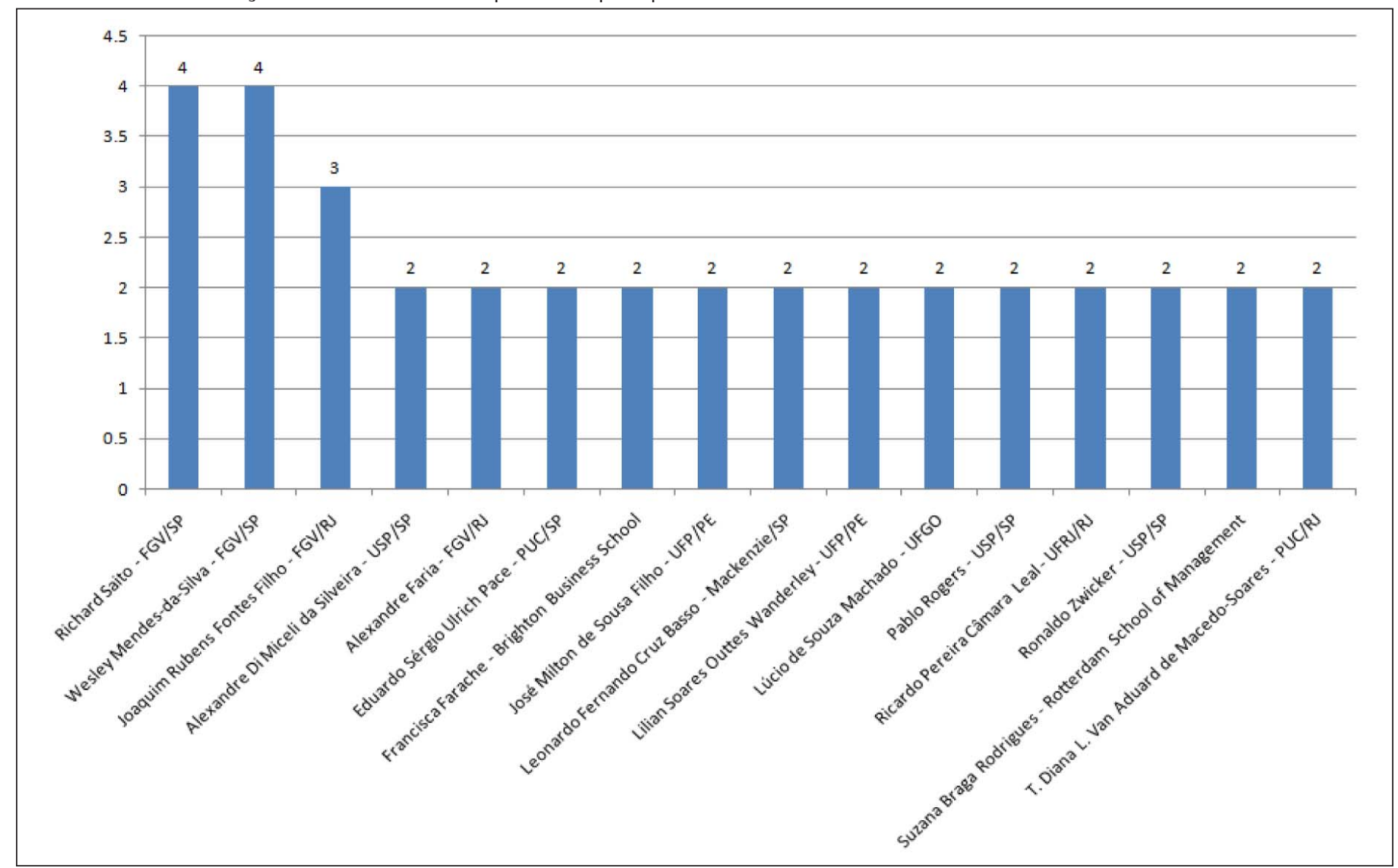


Ainda ao se analisar o Gráfico 4, remete-se à Lei de Lotka, a qual enfatiza que poucos pesquisadores publicam muito e muitos pesquisadores publicam pouco, mostrando assim o grau de relevância destes poucos autores para com a temática ora investigada. Diante do exposto, evidenciam-se outros estudos bibliométricos em outras áreas da Administração, que constataram a concentração da produção da área em um número restrito de pesquisadores, tais como: contábil (CARDoso et al., 2005; LeIte Filho, 2008; Mendonça Neto, Riccio \& SaKata, 2009; Cruz et al., 2011); estratégia (Bertero, Vasconcelos \& Binder, 2003; Machado-dA-Silva \& Rossoni, 2007); finanças (LeAL, OliveIRA \& Soluri, 2003); marketing (Chabowski, Mena \& Gonzalez-PAdron, 2011); produção (Grzebieluckas, CAMpos \& Selig, 2011); responsabilidade social corporativa (MoReTtI \& CAMPANÁRIO, 2009).

Constatou-se ainda que a maioria dos autores é oriunda de instituições de ensino superior (IES) do Sudeste, ou seja: FGV ${ }^{4}$, FEA/USP5, PUC ${ }^{6}$ e Mackenzie, todas de São Paulo; e FGV, UFRJ e PUC do Rio de Janeiro, sendo assim consideradas as que mais publicam sobre as temáticas de "governança corporativa" e "estratégia".

\subsection{Referências mais citadas}

A análise das referências pode ser vista como fator preponderante para a continuidade das pesquisas, pois se constatou que ela contemplará quais autores são mais citados em determinado tema, contribuindo e proporcionando um norte para pesquisadores experientes e, principalmente, para os iniciantes. 0 Gráfico 5 mostra a frequência de autores mais citados nos estudos nacionais integrados de "governança corporativa" e "estratégia".

Ao se verificar o Gráfico 5, verificou-se que os autores Michael E. Porter e Michael C. Jensen foram os mais citados nas referências sobre as temáticas integradas de "governança corporativa" e "estratégia" no período analisado, ou seja, ambos com 25 citações. Em seguida, foi contemplado o autor Oliver

\footnotetext{
${ }^{4}$ Fundação Getulio Vargas.

${ }^{5}$ Faculdade de Economia, Administração e Contabilidade da Universidade de São Paulo.

${ }^{6}$ Pontifícia Universidade Católica.

7 Universidade Federal do Rio de Janeiro.
}

E. Williamson, com 24 citações no total dos 79 artigos investigados. Logo na sequência, destacaram-se outros autores, que mais são citados. Ei-los: Alexandre D. M. Silveira, com 18 citações; William H. Meckling e Walter W. Powell, ambos com 16 citações; além de Julian Birkinshaw e Ricardo P. Câmara Leal, os dois com 15 citações. Destacaram-se, também, a CVM ${ }^{8}$ e o IBGC ${ }^{9}$ como as instituições que mais foram referendadas nos 79 artigos investigados, com 25 e 15 citações, respectivamente. Nota-se que a CVM, junto com os autores Porter e Jensen, foi também uma das mais referendadas no que tange às temáticas integradas de governança e estratégia.

Ressalta-se que os autores Alexandre D. M. da Silveira, Richard Saito e Wesley Mendes-da-Silva, além de serem os únicos pesquisadores brasileiros entre os que mais citados sobre os temas conjuntos "governança corporativa" e "estratégia", também são os que mais publicam sobre as temáticas em questão (Gráfico 4). Constatou-se também, ao se analisar o Gráfico 5, a presença de maioria absoluta de autores estrangeiros, principalmente da América do Norte, em especial dos Estados Unidos. Os achados descritos acima foram confirmados em parte pelos autores Serra \& Ferreira (2010) e Muritiba et al. (2010) em suas pesquisas bibliométricas de estratégia e governança corporativa, respectivamente.

Remetendo-se ao cenário acadêmico nacional, no que se refere à produtividade dos autores nacionais mais prolíferos, tal achado é corroborado pela Lei de Lotka ao entender-se que esta lei parte da premissa de que, proporcionalmente, poucos autores publicam mais e, consequentemente, são mais citados do que muitos autores que publicam menos (MoretTI \& Campanario, 2009). Ainda segundo os autores em destaque, tal constatação é visível em campos emergentes da ciência, como é o caso da governança corporativa.

\subsection{Referências por período}

A análise das referências abrange a quantidade de referências utilizadas nos 79 artigos investigados, permitindo assim identificar a evolução destas por

\footnotetext{
${ }^{8}$ Comissão de Valores Mobiliários.

${ }^{9}$ Instituto Brasileiro de Governança Corporativa.
} 
Gráfico 5: Autores mais citados no período pesquisado

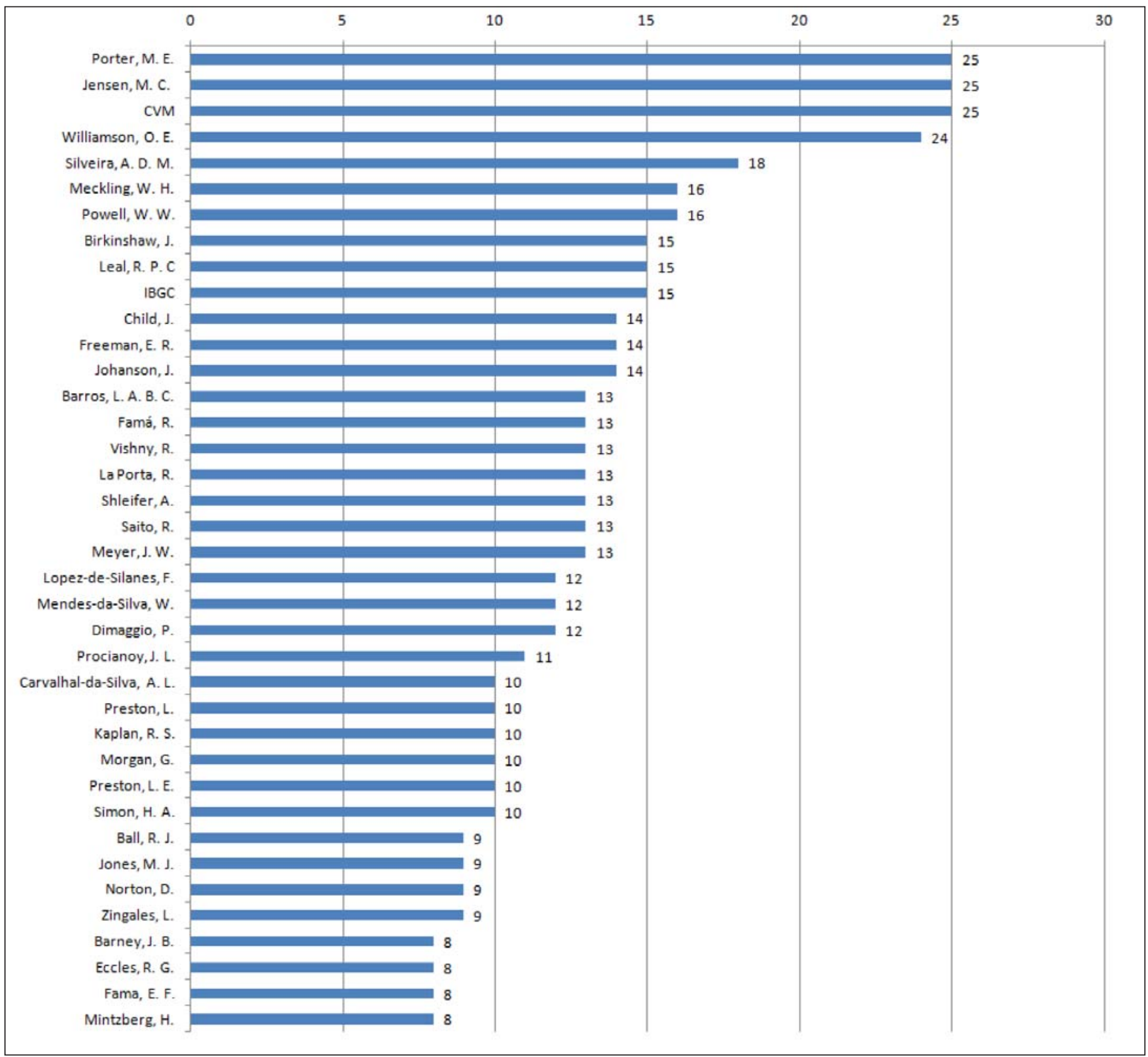

Fonte: elaborado pelos autores.

década e um breve panorama das quantidades de obras que tratam sobre os temas em conjunto a partir do início do século XXI. O Gráfico 6 mostra que, a partir da década de 1980 a 2000, houve um crescimento considerável das referências sobre as temáticas integradas de "governança corporativa" e "estratégia", ou seja, aproximadamente 365\%.

Ainda analisando-se o Gráfico 6, verificou-se que a maioria das referências investigadas nos 79 artigos da pesquisa é do ano de 2002. Tal fato pode ser explicado em virtude das primeiras pesquisas na década de 1980 e da suas consolidação na década de 1990 sobre "governança corporativa" e "estratégia", que impulsionaram e impactaram assim o surgimento de novas publicações que também se consolidaram e se tornaram importantes sobre o tema investigado (Gráfico 1). 
Gráfico 6: Idade das referências por década e por ano

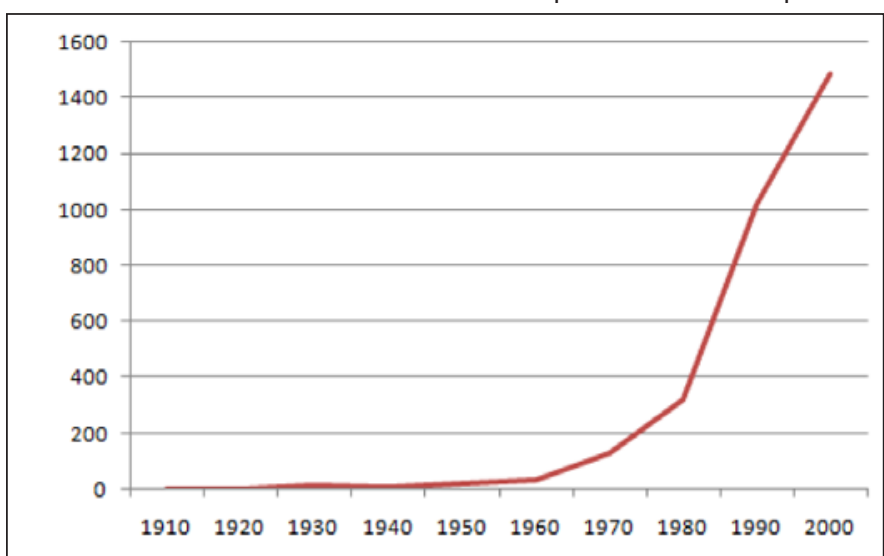

Fonte: elaborado pelos autores.

\subsection{Abordagens metodológicas}

Este item analisa as tipologias de pesquisa preferidas pelos artigos, de forma que se possa ter uma ideia da predominância destas tipologias pelos pesquisadores da área. Para fazer esta análise, foram utilizadas as informações fornecidas pelos próprios autores sobre o método que eles seguiram. Não cabe a este estudo julgar eventuais incongruências, já que se trata de artigos aprovados em revistas que possuem procedimentos de revisão.

Ao se analisar o Gráfico 7, verificou-se que a maioria dos artigos investigados nas pesquisas adota o enfoque quantitativo, ou seja, em 44 artigos, ao

Gráfico 7: Tipos de pesquisas utilizadas

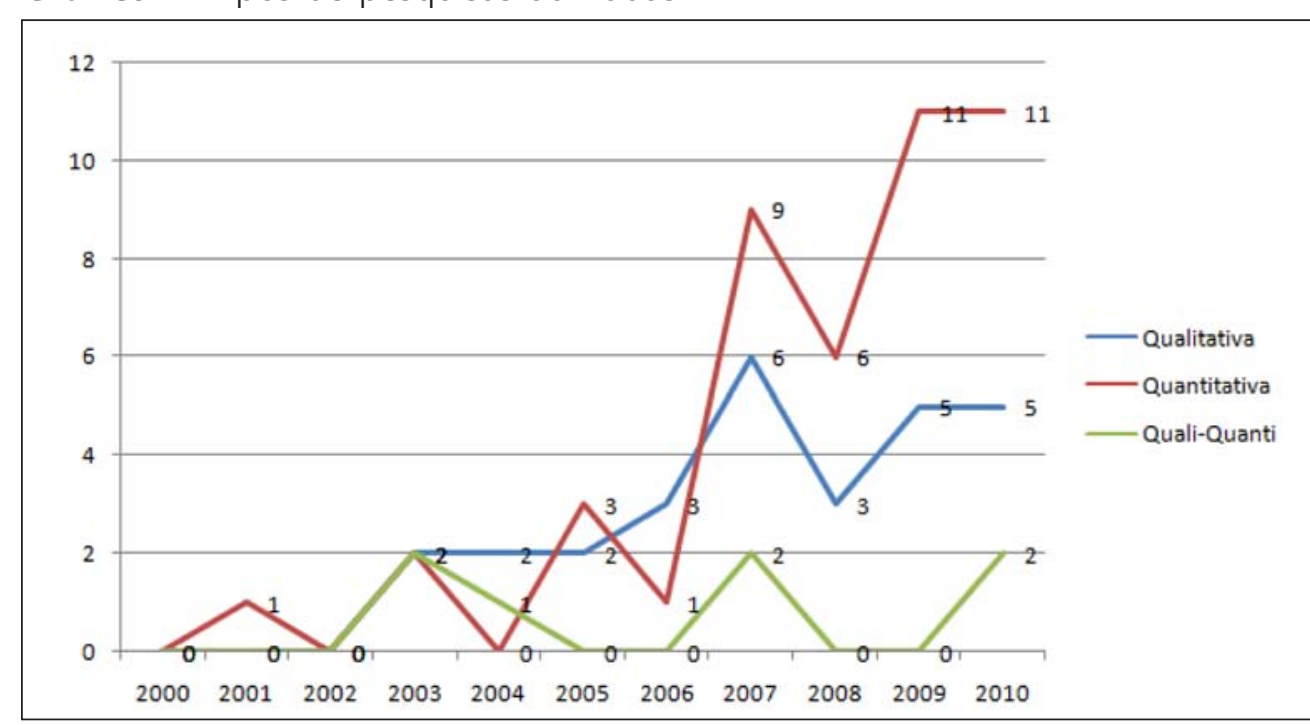

Fonte: elaborado pelos autores.

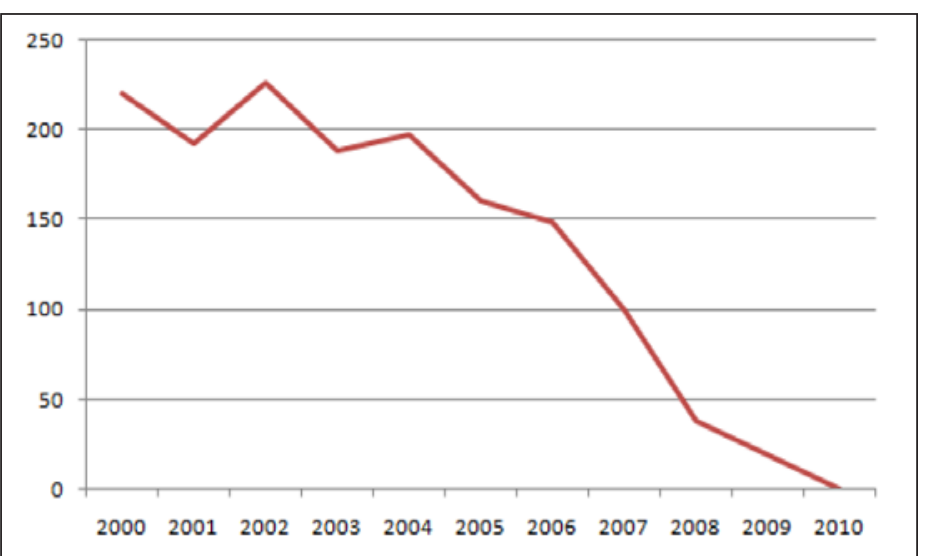

invés do qualitativo. Verificou-se também um crescimento da referida tipologia no período analisado.

Bertero, Vasconcelos \& Binder (2003), em sua pesquisa, constataram uma carência de estudos de cunho quantitativo. Ainda segundo estes autores, a predominância da pesquisa qualitativa não seguia, na época, a tendência da área de estratégia nos principais periódicos internacionais.

Já os autores Muritiba et al. (2010) constataram que a maioria dos artigos investigados em sua pesquisas adotava o enfoque quantitativo ao invés do qualitativo, podendo ser em decorrência do fato de que grande parte dos artigos pesquisados no período em questão trabalharam o tema "governança corporativa" com temas relacionados com Contabilidade, Economia e Finanças.

\section{CONCLUSÕES}

O presente trabalho investigou o perfil das pesquisas e o crescimento dos temas "governança corporativa" e "estratégia" em conjunto nos artigos publicados nas Revistas Qualis B2 a A1, no período de 2000 a 2010. Para tanto, efetuou-se uma análise bibliométrica em uma amostra de 79 artigos. Foi priorizado, na 
pesquisa, o foco nos seguintes critérios: (I) crescimento dos temas e periódicos de destaque; (II) características de autoria; (III) autores com maior produção nestes temas; (IV) referências mais citadas; $(V)$ referências por período; (VI) abordagens metodológicas.

Constatou-se a pouca ocorrência de estudos sobre governança corporativa e estratégia nos anos de 2000 a 2002, e um aumento substancial sobre os temas a partir de 2003, apresentando uma elevação percentual aproximado de $200 \%$ deste ano para 2010. Isto reflete a importância que as duas temáticas têm no cenário nacional, tanto no âmbito empresarial como na literatura acadêmica nacional.

Observou-se também que a adoção de boas práticas de governança corporativa, em especial aquelas legitimadas pelo mercado corporativo, têm impacto positivo na performance e na criação de valor das empresas, agregando também valor aos stakeholders que têm algum interesse e que compõem as organizações. Verificou-se, então, a relação direta das boas práticas com a estratégia organizacional.

Comprovou-se uma hierarquia de onde está publicada a maior parte dos artigos sobre governança corporativa e estratégia. Observou-se que 57\% dos artigos publicados estão contemplados nas revistas RAC, BAR e RAE. Notou-se, assim, a importância de tais periódicos para o crescimento dos temas estudados e para a área de administração, pois estão entre os extratos mais qualificados pela Capes, no triênio 2007 a 2009, ou seja, A2 a B1.

Evidenciaram-se os nomes de Richard Saito e Wesley Mendes-da-Silva como os autores mais profícuos sobre os temas "governança corporativa" e "estratégia" no período analisado, ou seja, quatro publicações. Em seguida, foi constatado o autor Joaquim Rubens Fontes Filho, com três artigos.

Observou-se que os autores Michael E. Porter e Michael $C$. Jensen foram os mais citados nas referências sobre as temáticas integradas de "governança corporativa" e "estratégia" no período analisado, ou seja, ambos com 25 citações. Michael E. Porter, em outros estudos bibliométricos com ênfase em estratégia, também foi evidenciado como o mais citado e importante na referida área enquanto o autor Jensen, ao descrever a teoria da agência, consolidou e legitimou de alguma forma a importância que as boas práticas de governança têm para a gestão e o controle das empresas.

Constatou-se que, a partir da década de 1980 a 2000, houve um crescimento considerável das referências sobre as temáticas "governança corporativa" e "estratégia" em conjunto, ou seja, aproximadamente $365 \%$, e que a maioria das referências investigadas nos 79 artigos da pesquisa é do ano de 2002. Isso mostra a importância dessas décadas para disseminar e fomentar os estudos sobre governança e estratégia, sendo no contexto individual ou em conjunto, que é o foco desta pesquisa.

Concluiu-se, neste estudo, de maneira geral, um perfil macro das publicações e do crescimento dos temas "governança corporativa" e "estratégia" em conjunto, analisando aspectos sobre as temáticas com o intuito de nortear e efetivamente contribuir com a melhoria e o fomento dos artigos sobre as áreas no meio acadêmico nacional.

Em suma, constatou-se a integração da governança corporativa com as estratégias adotadas pelas organizações por meio dos estudos investigados, ou seja, as boas práticas por meio de seus mecanismos têm relação direta com a gestão, e são extremamente relevantes para a estratégia empresarial das corporações.

Como limitação do estudo, ressalta-se que a amostra restringiu-se às publicações das Revistas Qualis B2 a A1 da área de Administração, deixando de considerar as áreas de Economia, Contabilidade e Finanças, que poderiam acrescentar mais informações ao que foi levantado.

Sugere-se, para futuros estudos, uma análise dos conteúdos (fundamentação teórica) abordados nos trabalhos. Isso proporcionará evidenciar, mediante comparação, como os temas integrados de "governança corporativa" e "estratégia" são vistos no mundo e na visão dos autores; um aprofundamento das abordagens metodológicas; e uma análise, por meio de um estudo sociométrico, para identificar as redes formadas por pesquisadores e IES. 
Alvarado, Rúben U. A bibliometria no Brasil. Ciência da Informação, v. 13, n. 2, p. 91-105, Brasília, julho/dezembro, 1984.

Araúso, Carlos Alberto. Bibliometria: evolução histórica e questões atuais. Em Questão, v. 12, n. 1, p. 11-32, Porto Alegre, janeiro/junho, 2006.

Bernard, Patrícia C. A evolução do conceito de governança corporativa à luz da ética: uma análise longitudinal. 2008. 149f. Dissertação (Mestrado em Administração de Empresas) - Fundação Getulio Vargas. São Paulo: FGV.

Bertero, Carlos Osmar; Vasconcelos, Flávio C. de. \& Binder, Marcelo P. Estratégia empresarial: a produção científica brasileira entre 1991 e 2002. Revista de Administração de Empresas, v. 43, n. 4, p. 48-62, São Paulo, outubro/ dezembro, 2003.

Bertucci, Janete Lara de O.; Bernardes, Patrícia \& BrandÃo, Mônica M. Políticas e práticas de governança corporativa em empresas brasileiras de capital aberto. Revista de Administração da USP, v. 41, n. 2, p. 183-196, São Paulo, abril/junho, 2006.

BianchI, Márcia; Silva, Carolina V. da \& Gelattı, Rosemary. A evolução e o perfil da governança corporativa no Brasil: um levantamento da produção científica do EnAnpad entre 1999-2008. In: XXXIII ENCONTRO dA AssociaÇäo Nacional dE Pós-Graduação e Pesquisa em Administração - EnAnpad. Anais Eletrônicos... São Paulo: Anpad, 2009. Disponível em: <http://www.anpad.org.br/evento.php?acao= trabalho\&cod_edicao_subsecao=506\& cod_evento_ edicao $=45 \&$ cod_edicao_trabalho $=10404>$. Acesso em: 8 de novembro de 2011.

Bogoni, Nadia M.; Zonatto, Vinícius C. da S.; IshiKURA, Edison R. \& Fernandes, Francisco Carlos. Proposta de um modelo de relatório de administração para o setor público baseado no parecer de Orientação n. 15/87 da Comissão de Valores Mobiliários: um instrumento de governança corporativa para a administração pública. Revista de Administração Pública, v. 44, n. 1, p. 119-142, Rio de Janeiro, janeiro/fevereiro, 2010.

BOYD, Brian K. CEO duality and firm performance: a contingency model. Strategic Management Journal, v. 16, n.4, p. 301-312, Malden, 1995.

BoWmAn, Edward $\mathrm{H}$. Some reflections on corporate strategy and corporate governance. International Studies of Management \& Organization, v. 9, n. 4, p. 100-107, Winter, 1979.

Bronzo, Marcelo \& HonórIo, Luiz. O institucionalismo e a abordagem das interações estratégicas da firma. RAE Eletrônica, v. 4, n. 1, p. 1-18, janeiro/junho, 2005.
Bufrem, Leilah S. \& Prates, Yara. O saber científico registrado e as práticas de mensuração da informação. Ciência da Informação, v. 34, n. 2, p. 9-25, Brasília, maio/agosto, 2005.

Capes - Coordenação de Aperfeiçoamento de Pessoal de Nível SuPerIor. Revistas Qualis. Disponível em: <http:// qualis.capes.gov.br/webqualis/ ConsultaListaCompletaPeriodicos.faces>. Acesso em: 5 de novembro de 2011.

Cardoso, Ricardo L.; Mendonça Neto, Otávio R. de; Riccio, Edson Luiz \& SAKATA, Marici Cristine G. Pesquisa cientifica em contabilidade entre 1990 e 2003. Revista de Administração de Empresas, v. 45, n. 2, p. 34-45, São Paulo, abril/junho, 2005.

Castro, Carmen B.; Concha, Marta D. de la; Gravel, Julio V. \& PERINAN, Ma Mar V. Does the team leverage the board's decisions? Corporate Governance: An International Review, v. 17, n. 6, p. 744-761, November, 2009.

Chabowski, Brian R.; Mena, Jeannette A. \& Gonzalez-Padron, Tracy $L$. The structure of sustainability research in marketing, 1958-2008: a basis for future research opportunities. Journal of the Academy of Marketing Science, v. 39, n. 1, p. 55-70, 2011.

Coluin, Sven-Olof \& Bengtsson, Lars. Corporate governance and strategy: a test of the association between governance structures and diversification on Swedish data. Corporate Governance: An International Review, v. 8, n. 2, p. 154165, April, 2000.

CoOper, Harris M. \& LINDSAY, James J. Research synthesis and meta-analysis. In: BICKMAN, Leonard \& RoG, Debra J. Handbook of applied social research methods. Thousand Oaks, CA: Sage Publications, 1998. p. 315-342.

Cruz, Ana Paula C. da; Espejo, Márcia Maria dos S. B.; CostA, Flaviano \& AlmeIDA, Lauro B. de. Perfil das redes de cooperação científica: congresso USP de controladoria e contabilidade de 2001 a 2009. Revista Contabilidade \& Finanças, v. 22, n. 55, p. 64-87, São Paulo, janeiro/abril, 2011.

Dedonatto, Omeri \& Beuren, Ilse Maria. Análise dos impactos para a contabilidade no processo de implantação da governança corporativa em uma empresa. Revista de Contabilidade e Controladoria, v. 2, n. 3, p. 23-38, Curitiba, setembro/dezembro, 2010.

Delgado, Ignácio G.; CondÉ, Eduardo Salomão; Ésther, Ângelo B. \& SAlLES, Helena da M. Cenários da diversidade: variedades de capitalismo e política industrial nos EUA, Alemanha, Espanha, Coreia, Argentina, México e Brasil (1998-2008). Dados - Revista de Ciências Sociais, v. 53, n. 4, p. 959-1.008, Rio de Janeiro, 2010. 


\section{REFERÊNCIAS}

Denis, David J.; DenIS, Diane K. \& SARIN, Atulya. Agency theory and the influence of equity ownership structure on corporate diversification strategies. Strategic Management Journal, v. 20, p. 1.071-1.076, Malden, November, 1999.

DOHERTY, Ane Marie. Explaining international retailer's market entry mode strategy: internalization theory, agency theory and the importance of information asymmetry. International Review of Retail, Distribution \& Consumer Research, v. 9, n. 4, p. 379-402, October, 1999.

Freeman, R. Edward \& Reed, David L. Stockholders and stakeholders: a new perspective on corporate governance. California Management Review, v. 25, n. 3, Spring, 1983.

García-Meca, Emma \& SÁnches-Ballesta, Juan P. Corporate governance and earnings management: a meta-analysis. Corporate Governance: An International Review, v. 17, n. 5, p. 594-610, September, 2009.

GazDA, Emmanuel \& Quandt, Carlos Olavo. Colaboração interinstitucional em pesquisa no Brasil: tendências em artigos na área de gestão da inovação. RAE Eletrônica, v. 9, n. 2, p. 1-27, são Paulo, julho/dezembro, 2010.

Grün, Roberto. Convergência das elites e inovações financeiras: a governança corporativa no Brasil. Revista Brasileira de Ciências Sociais, v. 20, n. 58, p. 67-90, São Paulo, junho, 2005.

Grzebieluckas, Cleci; Campos, Lucila Maria de S. \& Selig, Paulo Maurício. Contabilidade e custos ambientais: um levantamento da produção científica no período de 1996 a 2007. Produção, v. 21, n. 4, p. 1-11, São Paulo, October, 2011.

HuANG, Chiung-Yao \& Ho, Yuh-Shan. Historical research on corporate governance: a bibliometric analysis. African Journal of Business Management, v. 5, n. 2, p. 276-284, January, 2011.

Jensen, Michael C. \& MeCKLING, William H. Theory of the firm: managerial behavior, agency costs and ownership structure. Journal of Financial Economics, v. 3, n. 4, p. 177, July, 1976.

KoH, Ping-Sheng; Laplante, Stacie Kelley \& Tong, Yen H. Accountability and value enhancement roles of corporate governance. Accounting and Finance, v. 47, n. 2, p. 305333, June, 2007.

LeAL, Ricardo P. Câmara; OlivelRA, Jefferson de. \& Solurı, Aline F. Perfil da pesquisa em finanças no Brasil. Revista de Administração de Empresas, v. 43, n. 1, p. 91-104, São Paulo, janeiro/fevereiro/março, 2003.

LeITE FILHO, Geraldo Alemandro. Padrões de produtividade de autores em periódicos e congressos na área de contabilidade no Brasil: um estudo bibliométrico. Revista de Administração Contemporânea, v. 12, n. 2, p. 533554, Curitiba, abril/junho, 2008.

Machado-Da-Silva, Clóvis L. \& Rossonı, Luciano. Persistência e mudança de temas na estruturação do campo científico da estratégia em organizações no Brasil. Revista de Administração Contemporânea, v. 11, n. 4, p. 33-58, Curitiba, outubro/dezembro, 2007.

Marques, Daniel S. P. \& Costa, André L. Governança em clubes de futebol: um estudo comparativo de três agremiações no Estado de São Paulo. Revista de Administração da USP, v. 44, n. 2, p. 118-130, São Paulo, abril/junho, 2009.

Martins, Henrique C.; HILdebrand, Diofo F. N. \& Ziviani, Fabrício. Governança corporativa: um estudo da produção científica da Anpad no período de 2000 a 2007. In: XXXII Encontro da Associação Nacional de Pós-Graduação e Pesquisa em Administração - EnAnpad. Anais Eletrônicos... Rio de Janeiro: Anpad, 2008. Disponível em: <http://www. anpad.org.br/evento.php?acao=trabalho\& cod_edicao_ subsecao=391\&cod_evento_edicao=38\&cod_edicao_ trabalho=9607>. Acesso em: 8 de novembro de 2011 .

Mendes-da-Silva, Wesley. Governança corporativa e estratégia: evidências de associações e implicações para o desempenho financeiro de indústrias brasileiras. 2003. 197f. Dissertação (Mestrado em Administração) Universidade Federal de Pernambuco. Recife: UFPE.

Mendes-da-Silva, Wesley; Ferraz-Andrade, José Mauro; Famá, Rubens \& MALUf FILHo, José Arnaldo. Disclosure via website corporativo: um exame de informações financeiras e de governança no mercado brasileiro. Revista de Administração de Empresas, v. 49, n. 2, p. 190-205, São Paulo, abril/junho, 2009.

Mendonça Neto, Octávio R. de.; Riccio, Edson luiz \& Sakata, Marici Cristine G. Dez anos de pesquisa contábil no Brasil: análise dos trabalhos apresentados nos EnAnpads de 1996 a 2005. Revista de Administração de Empresas, v. 49, n. 1, p. 62-73, São Paulo, janeiro/março, 2009.

MintzBerg, Henry \& Quinn, James Brian. O processo da estratégia. Porto Alegre: Bookman, 2001.

Moretti, Sérgio Luiz do A. \& Campanario, Milton de A. A produção intelectual brasileira em responsabilidade social empresarial - RSE sob a ótica da bibliometria. Revista de Administração Contemporânea, v. 13, edição especial, p. 68-86, Curitiba, junho, 2009.

Muritiba, Sérgio N.; Ribeiro, Henrique César M.; Muritiba, Patrícia M. \& Domingues, Luciana M. Governança 
corporativa no Brasil: uma análise bibliométrica das publicações dos últimos doze anos. In: XIII Seminário em AdminISTRAÇÃo - Semead. Anais Eletrônicos... São Paulo: FEA USP, 2010. Disponível em: <http://www.ead.fea.usp.br/ semead/13semead/resultado/trabalhosPDF/887. pdf>. Acesso em: 8 de novembro de 2011.

Nascimento, Auster M.; Bianchi, Márcia \& Terra, Paulo Renato S. A controladoria como um mecanismo interno de governança corporativa: evidência de uma survey comparativa entre empresas de capital brasileiro e norteamericano. In: XXIX Encontro dA Associaçāo NACIONAL DE Pós-Graduação e Pesquisa em Administração - EnAnpad. Anais Eletrônicos... Brasília: Anpad, 2005. Disponível em: <http:/ /www.anpad.org.br/evento.php?acao=trabalho\&cod_ edicao_subsecao $=30 \&$ cod_evento_edicao $=9 \&$ cod_edicao _trabalho=497>. Acesso em: 30 de março de 2012.

NederHof, Anton J. Bibliometric monitoring of research performance in the social sciences and the humanities: a review. Scientometrics, v. 66, n. 1, p. 81-100, January, 2006.

Oman, Charles P. Corporate governance and national development. Technical Papers, n. 180. Paris, OECD Development Centre, 2001.

Pinto, Adilson Luiz; IGAMI, Mery P. Z. \& BressSIANI, José Carlos. Visibilidade e monitoramento científico na área nuclear e ciências relacionadas: uma perspectiva a partir da produtividade do Ipen-Cnen/SP. Perspectivas em Ciência da Informação, v. 15, n. 2, p. 198-218, Belo Horizonte, maio/agosto, 2010.

PoRTER, Michael E. Competição: estratégias competitivas essenciais. Rio de Janeiro: Elsevier, 1999.

Quoniam, Luc; Tarapanoff, Kira; Araújo Júnior, Rogério Henrique de. \& Alvares, Lilian. Inteligência obtida pela aplicação de data mining em base de teses francesas sobre o Brasil. Ciência da Informação, v. 30, n. 2, p. 20-28, Brasília, maio/agosto, 2001.

RoccA, Maurizio L. The influence of corporate governance on the relation between capital structure and value. Emerald Group Publishing Limited, v. 7, n. 3, October, 2007.

Rodrigues, Andréa L. \& Malo, Marie Claire. Estruturas de governança e empreendedorismo coletivo: o caso dos doutores da alegria. Revista de Administração Contemporânea, v. 10, n. 3, p. 29-50, Curitiba, julho/ setembro, 2006.

Rogers, Pablo; Mendes-da-Silva, Wesley \& Paula, Germano M. de. Diversificação e desempenho em empresas industriais brasileiras: um estudo empírico no período de 1997 a 2001. Revista de Administração Contemporânea, v. 12, n. 2, p. 313-338, Curitiba, abril/junho, 2008.

Rossoni, Luciano \& Machado-da-Silva, Clóvis L. Institucionalismo organizacional e práticas de governança corporativa. Revista de Administração Contemporânea, v. 14, número edição especial, p. 173-198, Curitiba, setembro, 2010.

Roth, Kendall \& O'DonnelL, Sharon. Foreign subsidiary compensation strategy: an agency theory perspective. Academy of Management Journal, v. 39, n. 3, p. 678703, junho, 1996.

SaIto, Richard \& Silveira, Alexandre D. M. da. Governança corporativa: custos de agência e estrutura de propriedade. Revista de Administração de Empresas, v. 48, n. 2, p. 7986, São Paulo, junho, 2008.

Santos, Silvio Omar L. dos; Antunes Júnior, José Antônio V. \& LEIS, Rodrigo P. Estratégia nos fundos de pensão do Brasil: contribuições para a construção de um modelo de análise. Revista de Administração Mackenzie, v. 9, n. 1, p. 37-63, São Paulo, 2008.

Saraiva, Ernani V. \& Carrierı, Alexandre de P. Citações e não citações na produção acadêmica de estratégia no Brasil: uma reflexão crítica. Revista de Administração da USP, v. 44, n. 2, p. 158-166, São Paulo, abril/maio/junho, 2009.

Serra, Fernando A. R. \& Ferreira, Manuel P. A evolução histórica do conhecimento em estratégia. Instituto Politécnico de Leitura - Working paper séries, p. 1-26, 2010.

Silveira, Alexandre D. M. da; Perobelli, Fernanda F. C. \& Barros, Lucas Ayres B. de C. Governança corporativa e os determinantes da estrutura de capital: evidências empíricas no Brasil. Revista de Administração Contemporânea, v. 12, n. 3, p. 763-788, Curitiba, julho/setembro, 2008.

Singleton Junior, Royce A. \& Straits, Bruce C. Approaches to social research. New York: Oxford University Press, 1999.

SouzA, Flávia C. de \& BorbA, José Alonso. Governança corporativa e remuneração de executivos: uma revisão de artigos publicados no exterior. Contabilidade Vista \& Revista, v. 18, n. 2, p. 35-48, Belo Horizonte, abril/junho, 2007.

Stroh, Linda K.; Brett, Jeanne M.; Baumann, Joseph P. \& Reilly, Anne H. Agency theory and variable pay compensation strategies. Academy of Management Journal, v. 39, n. 3, p. 751-767, June, 1996. 


\section{REFERÊNCIAS}

TESTA, James. A base de dados ISI e seu processo de seleção de revistas. Ciência da Informação, v. 27, n. 2, p. 233235, Brasília, maio/agosto, 1998.

VAn deR Walt, Nicholas T.; INGley, Coral B. \& Diack, Gary. Corporate governance: implications of ownership, performance requirements and strategy. Journal of Change Management, v. 2, n. 4, p. 319-333, June, 2002.

VANTI, Nádia Aurora P. Da bibliometria à webometria: uma exploração conceitual dos mecanismos utilizados para medir o registro da informação e a difusão do conhecimento. Ciência da Informação, v. 31, n. 2, p. 152162, Brasília, maio/agosto, 2002.

Walter, Silvana Anita; Lanza, Batriz B. B.; SATO, K. H.; Silva, Eduardo D. da. \& BACH, Tatiana M. Análise da produção científica de 1997 a 2009 na área de estratégia: produção e continuidade de atores e cooperação entre instituições brasileiras e estrangeiras. In: XXXIV EnCONTRO da Associação Nacional de Pós-Graduação e Pesquisa em AdminISTRAÇÃo - EnAnpad. Anais Eletrônicos... Rio de Janeiro: Anpad, 2010. Disponível em: <http://www.anpad.org.br/ evento.php?acao=trabalho\&cod_edicao_subsecao= 626\&cod_evento_edicao=53\&cod_edicao_trabalho=12095 $\mathrm{\text {. }}$. Acesso em: 08 de novembro de 2011.

Williamson, Oliver E. The economic institutions of capitalism: firms, markets, relational contracting. New York: The Free Press, 1985.

Zomignanı, Tatiana M. Governança corporativa e valor: relação entre as práticas de governança corporativa e o valor das empresas de capital aberto no mercado de capitais brasileiro. 2003. 90f. Dissertação (Mestrado em Administração de Empresas) - Fundação Getulio Vargas. São Paulo: FGV. 